\title{
A EXTENSÃO UNIVERSITÁRIA NO IFPB E SUA RELAÇÃO COM A SUSTENTABILIDADE EM CABEDELO/PB
}

\section{OUTREACH UNIVERSITY ACTIONS AT IFPB AND ITS RELATIONSHIP WITH SUSTAINABILITY IN CABEDELO/PB}

\author{
Renato Arcúrio Milagre* \\ ORCID: https://orcid.org/0000-0003-2571-3819 \\ Luiz Daniel Costa Falcão** \\ ORCID: https://orcid.org/0000-0003-1368-2429 \\ Ivan Targino Moreira*** \\ ORCID: https://orcid.org/0000-0002-2948-2926
}

\section{Resumo}

O objetivo desse estudo é analisar como as ações de extensão universitária do Instituto Federal da Paraíba (IFPB), em Cabedelo/PB, desenvolvem uma compreensão da comunidade acadêmica e municipal voltada para a sustentabilidade. A presente pesquisa é vinculada ao Mestrado Profissional em Políticas Públicas, Gestão e Avaliação da Educação Superior (MPPGAV), ofertado pela Universidade Federal da Paraíba (UFPB). Trata-se de um estudo de caso, com abordagem qualitativa e de natureza aplicada, em que o locus da investigação é o IFPB Campus Cabedelo. Assim, foram selecionados dois núcleos de extensão e buscou-se analisar as ações desenvolvidas a partir de cinco dimensões da sustentabilidade: social, ambiental, econômica, cultural e política. Nesse sentido, os resultados encontrados demonstram que a instituição desenvolve ações de extensão universitária que englobam as diversas dimensões da sustentabilidade. Por conseguinte, é de fundamental importância que o IFPB intensifique estratégias que venham a maximizar o potencial extensionista da instituição.

Palavras-chave: Extensão universitária; Sustentabilidade; Desenvolvimento sustentável.

\begin{abstract}
This study analyzes how the outreach university actions of the Federal Institute of Paraíba (IFPB, Portuguese acronym), in Cabedelo / PB, develop the understanding of sustainability_of the academic and municipal community. The research is linked to the Professional Master's Program in Public Policies, Management and Evaluation of Higher Education (MPPGAV, Portuguese acronym), offered by the Federal University of Paraíba (UFPB, Portuguese acronym). The case study was carried out according to an applied qualitative approach that investigated the IFPB - Campus Cabedelo. Thus, two outreach centers were selected in order to analyze the actions developed considering the five dimensions of sustainability: the social, environmental, economic, cultural and political dimensions. In this sense, the results demonstrate that the institution develops university outreach actions that include the various dimensions of sustainability. Therefore, it is of paramount importance that the IFPB strengthens strategies that maximize the potential of its outreach activities.
\end{abstract}

Keywords: Outreach university actions; Sustainability; Sustainable development. 


\section{Introdução}

O sistema de educação no Brasil surgiu e evoluiu de maneiras distintas e com características específicas em cada período histórico. À vista disso, o modelo de educação superior adotado atualmente no Brasil possui diversas características divergentes do modelo adotado em seu surgimento. Nesse sentido, a Extensão Universitária foi introduzida no ensino superior com as reformas e avanços da educação.

Destaca-se que, ao longo da história, a Extensão Universitária nem sempre foi considerada relevante no contexto da educação superior, tendo em vista que a universidade brasileira surge com a missão inicial voltada apenas para o ensino. Posteriormente, engloba a pesquisa associada ao ensino e, por último, compreende a importância da extensão para formar o tripé do sistema universitário.

De acordo com Hunger et al. (2014), na década de 1960, a universidade era apenas direcionada para o ensino e só com a Reforma Universitária (Lei n. 5.540/68) surge a pesquisa em sua atividade principal. Assim, o ensino e a pesquisa passam a ser articulados e inseparáveis. De acordo com o art. $2^{\circ}$ da referida lei, "O ensino superior, indissociável da pesquisa, será ministrado em universidades e, excepcionalmente, em estabelecimentos isolados, organizados como instituições de direito público ou privado".

Segundo Buffa e Pereira (2007), a reforma universitária, por meio da Lei $n^{\circ}$ 5.540/68, eliminou o sistema de cátedra, abriu espaço para a contratação de professores em regime de tempo integral e impôs, para a universidade, um tripé composto do ensino, pesquisa e extensão. Entretanto, os autores enfatizam o fato de que a extensão universitária ainda se encontra atrofiada.

Esse surgimento tardio traz reflexos até os dias atuais nas relações com a extensão, portanto, é de fundamental importância compreender a sua relevância para estabelecer uma educação complexa e integrada, em que a universidade se insere no contexto social e não apenas se fecha nos conhecimentos científicos.

Somado a isso, é importante destacar a importância da sustentabilidade, em suas variadas dimensões, para a construção de ações voltadas para o desenvolvimento da sociedade em que as instituições de ensino estão inseridas.

Assim, inicialmente, é importante definir o conceito do termo sustentabilidade que irá nortear o desenvolvimento do presente estudo. Não existe, atualmente, uma definição exata sobre o termo sustentabilidade, porém, diversos autores apresentam sua visão voltada para a responsabilidade ambiental. Destarte, Castro (1996) informa que apesar de sua origem vinculada ao manejo durável dos ecossistemas, a ideia de sustentabilidade é suficientemente rica para poder ser integrada numa visão multidimensional de desenvolvimento. Sendo assim, para esta pesquisa serão utilizadas as seguintes categorias da sustentabilidade: Social, Ambiental, Econômica, Cultural e Política. 
Portanto, para compreender essa relação entre sustentabilidade e extensão universitária, foi definido como objeto dessa pesquisa o Instituto Federal da Paraíba (IFPB), tendo em vista o realce que tem sido dado às atividades extensionistas. Dessa forma, esta pesquisa se propõe a buscar a resposta da seguinte questão: A extensão universitária desenvolvida no Campus Cabedelo tem contribuído para a questão da sustentabilidade do município?

\section{Procedimentos Metodológicos}

A presente pesquisa, vinculada ao Mestrado Profissional em Políticas Públicas, Gestão e Avaliação da Educação Superior (MPPGAV), ofertado pela Universidade Federal da Paraíba, possui como objetivo analisar como as ações de extensão universitária do IFPB, em Cabedelo/PB, desenvolvem uma compreensão da comunidade acadêmica e municipal voltada para a sustentabilidade.

A análise de conteúdo constitui-se como uma metodologia de pesquisa utilizada para descrição e interpretação do conteúdo de uma classe de documentos e texto para a realização de uma descrição sistemática, qualitativa ou quantitativa, visando a atingir uma compreensão maior dos significados. Essa metodologia vai além de uma simples análise de dados, figurando como uma abordagem metodológica com características próprias (NEUENDORF, 2002).

A referida análise apresenta como etapa específica à fase de planejamento, coleta e sistematização dos dados. As outras fases de cunho analítico dependem de uma coleta realizada adequadamente. Assim, para o fomento deste estudo de cunho bibliográfico, foram utilizadas obras completas pesquisadas, artigos, monografias, teses e dissertações anteriormente publicadas, com a finalidade de analisar como as ações de extensão universitária do Instituto Federal da Paraíba (IFPB), em Cabedelo/PB, desenvolvem uma compreensão da comunidade acadêmica e municipal voltada para a sustentabilidade.

Segundo Bardim (2011), existem algumas regras que precisam ser seguidas para o desenvolvimento de uma pesquisa que envolva uma análise de conteúdo, especialmente no que tange às categorias, considerando os aspectos intrínsecos da matéria prima de análise, do contexto da pesquisa e das inferências pretendidas. Há cinco regras para o fomento de uma análise de conteúdo:

- Inclusão e exclusão de categoriais;

- Homogeneidade;

- Exclusividade;

- Exaustividade;

- Confiabilidade. 
A análise de conteúdo deve especificar quais os sinais que devem ser classificados e em que categorias. As categorias não podem apresentar elementos que se sobreponham, ou seja, redundantes, que resultem em mensagens que se encaixem em mais de uma categoria, pois tal fato levaria à ausência de confiabilidade. As categorias precisam ser válidas, isto é, adequadas aos objetivos da análise, à natureza do material analisado e às questões que se pretende responder por meio da pesquisa. A exaustividade define que um conjunto de categorias deve possibilitar a categorização de todo o conteúdo significativo definido em conformidade com os objetivos da análise. A homogeneidade considera que a organização da análise de conteúdo deve fundamentarse em um único princípio ou critério de classificação. Numa perspectiva quantitativa, deve basearse numa única variável. Já a exclusividade considera que o analista de conteúdo assegure que cada elemento seja classificado em apenas uma categoria (BARDIM, 2011).

De acordo com Olabuenaga e Ispizuá (1989), a categorização refere-se ao agrupamento de dados considerando o que eles têm em comum. A classificação dá-se por semelhança ou analogia, segundo critérios previamente estabelecidos. Desse modo, foram utilizados como critérios de inclusão: obras literárias e artigos com disponibilidade do texto completo, sem restrições de idiomas e sem corte temporal. Foram excluídos os artigos duplicados, aqueles que não tinham texto completo disponível e aqueles que não apresentavam relação com a temática. A estratégia de busca desta pesquisa utilizou-se dos seguintes descritivos: "sustentabilidade"; "desenvolvimento sustentável"; "extensão universitária"; "universidade"; em português, inglês e espanhol. Os estudos selecionados foram lidos, analisados, confrontados e os resultados foram apresentados de forma conceitual.

Assim, a respeito do método de procedimentos escolhido para o desenvolvimento desta pesquisa, optou-se pelo estudo de caso. De acordo com Gil (2002, p. 54), o estudo de caso permite uma análise profunda e exaustiva de um ou poucos objetos, isso permite um maior detalhamento do conhecimento.

Quanto à natureza da pesquisa, entende-se que ela se caracteriza como aplicada, pois permite uma aplicação prática e busca resolver problemas específicos, ou seja, será possível compreender as particularidades da realidade do IFPB - Campus Cabedelo e com isso propor ações de resolubilidade para os núcleos de extensão da instituição.

Sobre a pesquisa aplicada, Prodanov e Freitas (2013, p. 22) afirmam que sob a perspectiva de sua natureza, esse tipo de pesquisa resulta em conhecimentos de aplicação prática e dirigidos à solução de problemas específicos, dessa forma, abordando interesses locais. Já sob a perspectiva dos objetivos da pesquisa, caracteriza-se como exploratória, ou seja, há uma coerência com os procedimentos metodológicos já citados anteriormente. Essa perspectiva permitirá uma análise mais complexa e abrangente do objeto de estudo.

Do ponto de vista de abordagem do problema, o enfoque da corrente pesquisada é qualitativo, pois permite delimitar com precisão as variáveis a serem estudadas, o que pode dar mais foco no estudo. Assim, Prodanov e Freitas (2013, p.70) fazem a seguinte consideração a respeito da pesquisa qualitativa: 


\begin{abstract}
A interpretação dos fenômenos e a atribuição de significados são básicas no processo de pesquisa qualitativa. Esta não requer o uso de métodos e técnicas estatísticas. O ambiente natural é a fonte direta para coleta de dados e o pesquisador é o instrumento-chave. Tal pesquisa é descritiva. Os pesquisadores tendem a analisar seus dados indutivamente. $\mathrm{O}$ processo e seu significado são os focos principais de abordagem (PRODANOV e FREITAS, 2013, p.70).
\end{abstract}

A análise de conteúdo em sua dimensão qualitativa considera diversos pressupostos que servem de suporte para identificar seu sentido simbólico, sendo que o mesmo poderá ter enfoque em diversas perspectivas, como esclarecem Olabuenaga e Ispizúa (1989).

Para definir a amostra da pesquisa, foi necessário consultar os núcleos de extensão existentes na instituição, assim, identificou-se que atualmente no Campus Cabedelo existem sete núcleos permanentes de extensão, porém foram escolhidos apenas dois núcleos para esta pesquisa: Núcleo de Pesquisa e Defesa do Patrimônio Cultural de Cabedelo (NUPACC) e Núcleo de Mãos Dadas com a Comunidade (DMDC). Tal escolha foi baseada em informações coletadas na Coordenação de Pesquisa e Extensão do Campus, ou seja, foram escolhidos os núcleos que mais se destacam no município.

As variáveis quantitativas são as características que podem ser medidas em uma escala mediante a apresentação de valores numéricos. Nesse sentido, a amostra definida para a realização das entrevistas foi estabelecida para abranger os diversos segmentos envolvidos com a extensão universitária, ou seja: 02 (dois) coordenadores dos núcleos de extensão; 08 (oito) membros da comunidade de Cabedelo participantes dos projetos de extensão; 01 (um) coordenador de Pesquisa/Extensão da instituição; 04 (quatro) parceiros sociais dos projetos e 04 (quatro) discentes que participam ou participaram dos projetos de extensão universitária, totalizando 19 (dezenove) entrevistados.

Os participantes foram identificados ao longo desse estudo da seguinte forma: Coordenador de Pesquisa e Extensão do Campus Cabedelo (CPEX-CB); Coordenadora do DMDC; Coordenadora do NUPACC; Discentes Bolsistas (D1 a D4); Membros da Comunidade (MC1 a MC8) e os Parceiros Sociais (PS1 a PS4).

Como ferramenta de coleta de dados, foi utilizada a observação e a entrevista com questões semiabertas. Essas entrevistas foram gravadas e, posteriormente, transcritas para que os dados coletados pudessem ser analisados. Destaca-se que foi informado aos entrevistados os objetivos dessa pesquisa e todos assinaram o Termo de Consentimento Livre e Esclarecido (TCLE) e o Termo de Assentimento (TA).

Por intermédio do método indutivo analítico, buscou-se avaliar os seguintes aspectos:

a) compreensão dos entrevistados sobre Sustentabilidade;

b) relação da Extensão Universitária com a Sustentabilidade;

c) envolvimento da Universidade com ações sustentáveis;

d) dimensões da sustentabilidade afetadas pela referida atuação. 
Por fim, é fundamental ressaltar que este estudo garantiu o anonimato de todos os participantes e foram cumpridos os princípios éticos contidos na Declaração de Helsinki (1964, reformulada em 1975, 1983, 1989, 1996 e 2000), da World Medical Association (http://www.wma.net/e/policy/b3.htm).

\section{Breve Histórico da Extensão Universitária no Brasil}

O processo de surgimento das universidades no Brasil ocorreu de maneira tardia em comparação com outros países latino-americanos. Desse modo, o contexto histórico, as características particulares do país, os aspectos políticos e demais fatores influenciaram no estilo de instituições estabelecidas em terras brasileiras.

Com relação aos aspectos históricos da Extensão no Brasil, Jezine (2006, p. 147) aponta a Carta de Córdoba (1918) como a principal referência do movimento estudantil latinoamericano, que defendia uma universidade aberta e a criação de um Departamento de Extensão. Nesse sentido, a autora faz a seguinte consideração:

\section{[...] a extensão, no Brasil, se consolidou a partir da criação da Escola Superior de Agricultura e Veterinária de Viçosa, criada em 1920 e inaugurada em 1926, tendo vindo para sua implementação o Professor Henry Rolfs, diretor do Florida Agicultural College dos Land Grant Colleges. A Semana do Fazendeiro (1929) foi a primeira experiência sistemática que deu forma a este modelo de prestação de serviços ao meio rural (JEZINE, 2006, p. 147).}

Já de acordo com Frizzo, Marin e Schellin (2016, p. 631), "a extensão se constituiu prioritariamente sob a forma de prestação de serviços, cursos profissionalizantes, educação à distância, dentre outros modelos e metodologias", ou seja, baseada no modelo norte americano de extensão.

Seguindo o modelo norte americano, a primeira legislação que abordou a extensão universitária no Brasil buscava a difusão de aspectos técnicos e científicos. Sendo assim, a principal forma de efetivação dessas atividades dava-se por meio da realização de cursos, principalmente aqueles voltados para a área agrícola.

Avançando no processo de contextualização para a compreensão da extensão universitária, Bottoni et al. (2013, p. 25) analisaram a educação superior no Brasil em dois momentos, "no primeiro, o ensino superior caracterizou-se pelo desenvolvimento das escolas profissionalizantes, como as de Medicina, e, no segundo, com a expansão das escolas de Filosofia, Ciências e Letras, Economia, entre outras".

Os autores realizaram um levantamento histórico no país desde o surgimento dessas primeiras instituições de ensino superior, em 1808, passando pelo reconhecimento oficial da primeira universidade, em 1920, Universidade do Rio de Janeiro, até o período atual. 
Com isso, é possível perceber que as dimensões ensino, pesquisa e extensão tiveram início em períodos distintos e foram sofrendo mudanças em suas características no decorrer da história. Ademais, compreende-se que, ao longo do tempo, a extensão universitária vem sendo percebida de maneiras distintas ou até inadequadas pelos membros ligados diretamente ou indiretamente à academia.

Moimaz et al. (2015, p. 14) afirmam que "No entanto, apesar de sua importância, no Brasil, a extensão ainda não consegue atingir o caráter de igualdade e indispensabilidade frente à formação profissional, quando comparada ao ensino e à pesquisa".

Com isso, entende-se que devido a sua complexidade, envolvendo questões inter e transdisciplinar, a extensão universitária apresenta aspectos particulares que necessitam de maiores estudos para compreensão de sua origem e sua dinâmica no contexto acadêmico.

O Fórum de Pró-Reitores de Extensão das Instituições Públicas de Educação Superior Brasileiras (FORPROEX) assumiu uma postura determinante e essencial para o avanço da extensão em diversos aspectos. Assim, o Fórum chegou ao seguinte conceito, "A extensão universitária é o processo educativo, cultural e científico que articula o ensino e a pesquisa de forma indissociável e viabiliza a relação transformadora entre a universidade e a sociedade" (FORPROEX, 1987, p. 11).

A partir das informações destacadas, é possível compreender a importância do FORPROEX no fortalecimento da extensão universitária no país. Entretanto, em relação a essa conceituação, Rovati e D'Ottaviano dizem que:

A referência à Extensão Universitária sempre vem acompanhada da definição sobre o tripé ensino-pesquisa-extensão, que supostamente sustentaria as universidades brasileiras. No entanto, em nossa prática cotidiana, sabemos que nesse tripé a extensão é o “primo pobre” (ROVATI; D’OTTAVIANO, 2017, p.20).

A fala dos autores está em consonância com o Fórum de Pró-Reitores de Extensão das Instituições Públicas de Educação Superior Brasileiras (2012) que apresenta, atualmente, a seguinte definição:

\footnotetext{
A Extensão Universitária, sob o princípio constitucional da indissociabilidade entre ensino, pesquisa e extensão, é um processo interdisciplinar, educativo, cultural, científico e político que promove a interação transformadora entre a universidade $\mathrm{e}$ outros setores da sociedade (FORPROEX, 2012, p. 28).
}

Rovati e D'Ottaviano (2017) ainda completam informando que não é interessante debater o tema com objetivo de encontrar um conceito definitivo, mas sim com a intenção de saber com quem e sobre o que se está falando. Além disso, destacam a necessidade de não se descartar a história e as práticas nesse processo de conceituação. 
Com isso, vale salientar a importância do papel que a universidade desempenha atualmente como instituição integrante da sociedade. Portanto, é relevante compreender esse papel em relação ao desenvolvimento de ações voltadas à sustentabilidade.

\section{Universidade e Sustentabilidade}

Dentre as medidas que a universidade pode desenvolver visando à melhoria dos diversos membros da sociedade, encontram-se as ações de sustentabilidade. Assim, essas ações podem proporcionar melhores condições de vida da comunidade de forma geral.

Antes de continuar, vale destacar que o conceito de sustentabilidade, assim como ocorre com o conceito de extensão universitária, não é consensual entre os pesquisadores da área. Todavia, destaca-se que a grande maioria acredita que analisar a sustentabilidade apenas como fatores ambientais é tratar o tema com reducionismo.

A respeito do conceito deste termo, Póvoas $(2015$, p. 14) afirma que "O conceito de Sustentabilidade foi construído a partir de uma tríplice dimensão: ambiental, econômica e social". Assim, percebe-se que essa tríplice compreensão exerce uma forte influência a respeito do conceito de sustentabilidade até os dias atuais, entretanto, a autora completa ressaltando que:

A deterioração material do planeta é insustentável, mas a pobreza também é insustentável, a exclusão social também é insustentável, assim como a injustiça, a opressão, a escravidão e a dominação cultural e econômica. A Sustentabilidade compreende não somente na relação entre econômico e ambiental, mas do equilíbrio humano frente às demais problemáticas (PÓVOAS, 2015, p. 50).

Além disso, Sachs (2002, p. 85-88) amplia a concepção desse conceito indicando, em seus estudos mais recentes, oito dimensões para o termo sustentabilidade: ambiental, econômica, social, cultural, territorial, ecológica, política nacional e política internacional. Entretanto, em estudos mais recentes, identifica-se que, além dessas dimensões propostas por Sachs, estudiosos desse tema mantém um contínuo estudo e desenvolvem novas teorias a respeito da sustentabilidade. Iaquinto (2018) elucida:

\footnotetext{
Neste sentido, analisou-se a presença de dimensões da sustentabilidade em várias áreas das relações humanas, sendo constatado a existência de dez dimensões, quais sejam: dimensão ecológica ou ambiental, dimensão econômica, dimensão social, dimensão espacial ou territorial, dimensão cultural, dimensão política (nacional e internacional), dimensão jurídico-política, dimensão ética, dimensão psicológica e dimensão tecnológica (IAQUINTO, 2018, p. 175).
}

Contudo, como não existe um consenso sobre a sustentabilidade entre os estudiosos dessa temática. Nesta pesquisa, será adotado um conjunto de cinco dimensões da sustentabilidade que se baseiam em estudos mais recentes: Social, Ambiental, Econômica, Cultural e Política. 
Portanto, a busca pelo desenvolvimento sustentável é uma das atribuições das instituições de ensino. Consequentemente, o IFPB, enquanto instituição de ensino, também é responsável pela articulação de ações que estimulem o desenvolvimento da comunidade em que está inserido, além disso, essa busca pelo desenvolvimento faz parte de sua missão institucional e integra a instituição desde sua origem.

Assim, para compreender melhor a atuação do IFPB, mais especificamente do Campus Cabedelo, é importante analisar o contexto histórico de surgimento da instituição e enfatizar as ações desenvolvidas pelos núcleos de extensão da unidade.

\section{O Instituto Federal da Paraíba}

O IFPB caracteriza-se como instituição pluricurricular que busca, por meio da articulação entre o Ensino, a Pesquisa e a Extensão, contribuir para a formação de cidadãos e para o desenvolvimento da sociedade. Possui como missão: "auxiliar no processo de construção de uma sociedade justa, sustentável e democrática” (IFPB, PDI 2015-2019).

Vale destacar que o IFPB passou por diversos processos de mudança em sua identidade organizacional e estrutura ao longo dos anos. Desde o seu surgimento até os dias atuais, a instituição vem se adaptando e se reinventando para conseguir se enquadrar nos novos modelos aos quais foi submetida. Portanto, esse processo histórico acarretou mudanças contínuas em suas atividades.

Com relação à atuação do Campus Cabedelo, locus da pesquisa, percebe-se que essa unidade possui amplo destaque em relação às práticas extensionistas. Ademais, esse Campus também precisa propor e desenvolver mecanismos para alcançar o desenvolvimento sustentável e proporcionar melhorias para a comunidade em que está inserido. Por fim, destaca-se que esse estudo pretende trazer contribuições práticas e efetivas à instituição, tendo em vista que o pesquisador responsável também atua como servidor público na referida unidade.

Como uma das formas de desempenhar o seu papel social, o Campus oferta educação profissional, de maneira que ensino, pesquisa e extensão sejam indissociáveis. Com isso, são estimuladas as potencialidades de Cabedelo, observando sempre a questão da sustentabilidade. Por conseguinte, é importante compreender as ações desenvolvidas pelos núcleos de extensão previamente selecionados para este estudo.

O Núcleo de Mãos Dadas com a Comunidade tem o objetivo de desenvolver ações que auxiliem a comunidade em todo processo relacionado ao processamento de pescados, ou seja, desde a higienização e elaboração de produtos pesqueiros até a reciclagem dos resíduos orgânicos. Já o Núcleo de Pesquisa e Defesa do Patrimônio Cultural de Cabedelo busca auxiliar no processo de conscientização da comunidade referente à preservação do patrimônio cultural do município. 


\section{Resultados e Discussão}

Para compreender a relação entre sustentabilidade e extensão universitária, as entrevistas realizadas foram analisadas e descritas via método de Indução Analítica, que é uma estratégia de pesquisa destinada a desenvolver sistematicamente considerações causais para diversas espécies de fenômenos (BARDIM, 2011). As entrevistas foram avaliadas considerando o conhecimento da sustentabilidade e sua amplitude; compreensão da importância da Extensão Universitária com a sustentabilidade; envolvimento dos parceiros e as dimensões da sustentabilidade.

Ao analisar as falas dos entrevistados, é possível perceber que o termo sustentabilidade foi relacionado por todos os participantes com o meio ambiente, isto é, dos 19 entrevistados, todos relacionaram a sustentabilidade a questões ambientais. Dessa forma, é possível confirmar algo já mencionado no referencial teórico desta pesquisa, ou seja, a sustentabilidade ainda é vista de maneira reducionista e relacionada com questões ambientais. Entretanto, todas as cinco dimensões aqui analisadas foram citadas pelos entrevistados, destacando-se as três dimensões básicas (Ambiental, Social e Econômica), conforme demonstra o gráfico abaixo.

Gráfico 1 - Dimensões da sustentabilidade

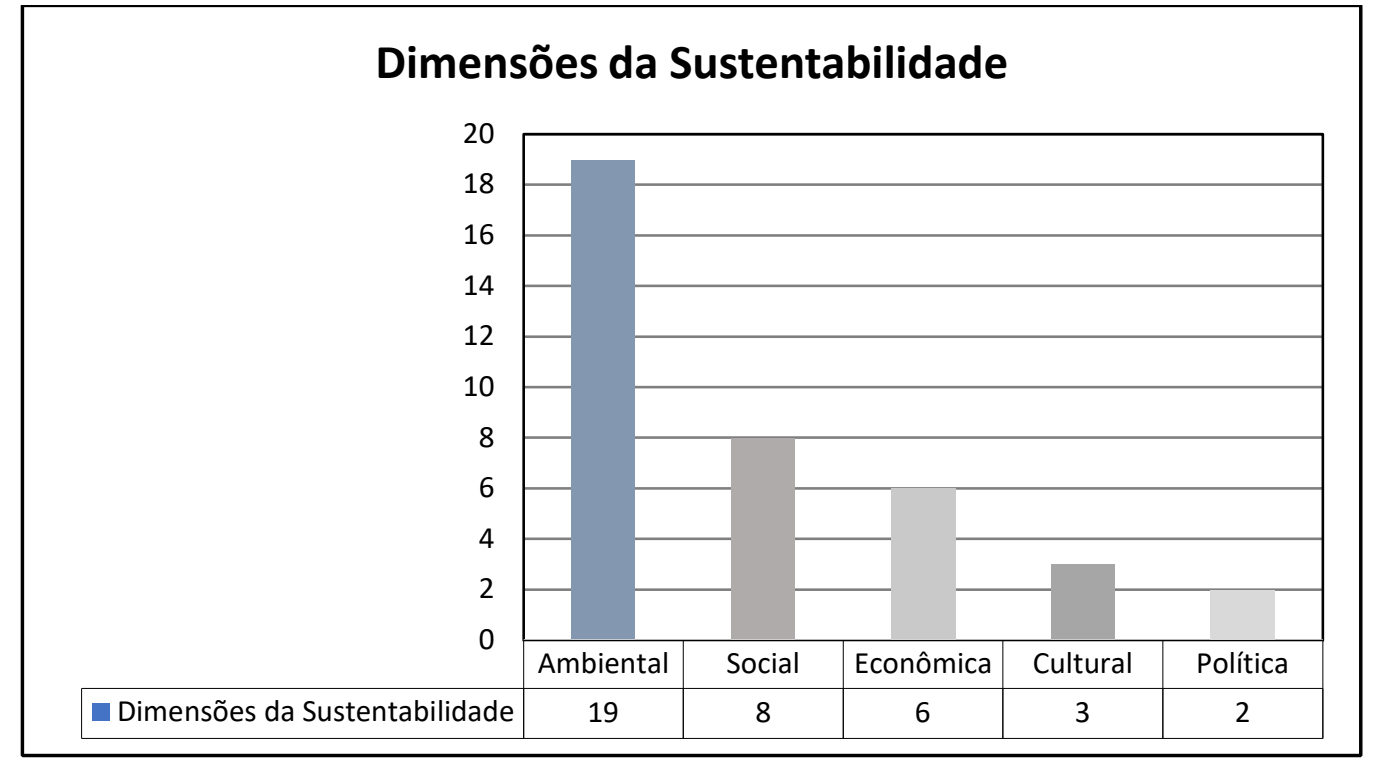

Fonte: Elaborado pelo autor

Já em relação à Extensão Universitária foi possível identificar dois entendimentos gerais: o primeiro aborda uma relação de parceria/troca entre o IFPB e a comunidade para alcançar melhorias para o município; já o segundo entendimento coloca a instituição como o agente ativo responsável por essas ações e a comunidade apenas como agente receptivo. Vale 
destacar que dos dezenove entrevistados, doze acreditam nessa relação de trabalho em conjunto, enquanto apenas sete enxergam a extensão como responsabilidade exclusiva do instituto, como evidenciado no próximo gráfico.

Gráfico 2 - Atuação da Extensão Universitária

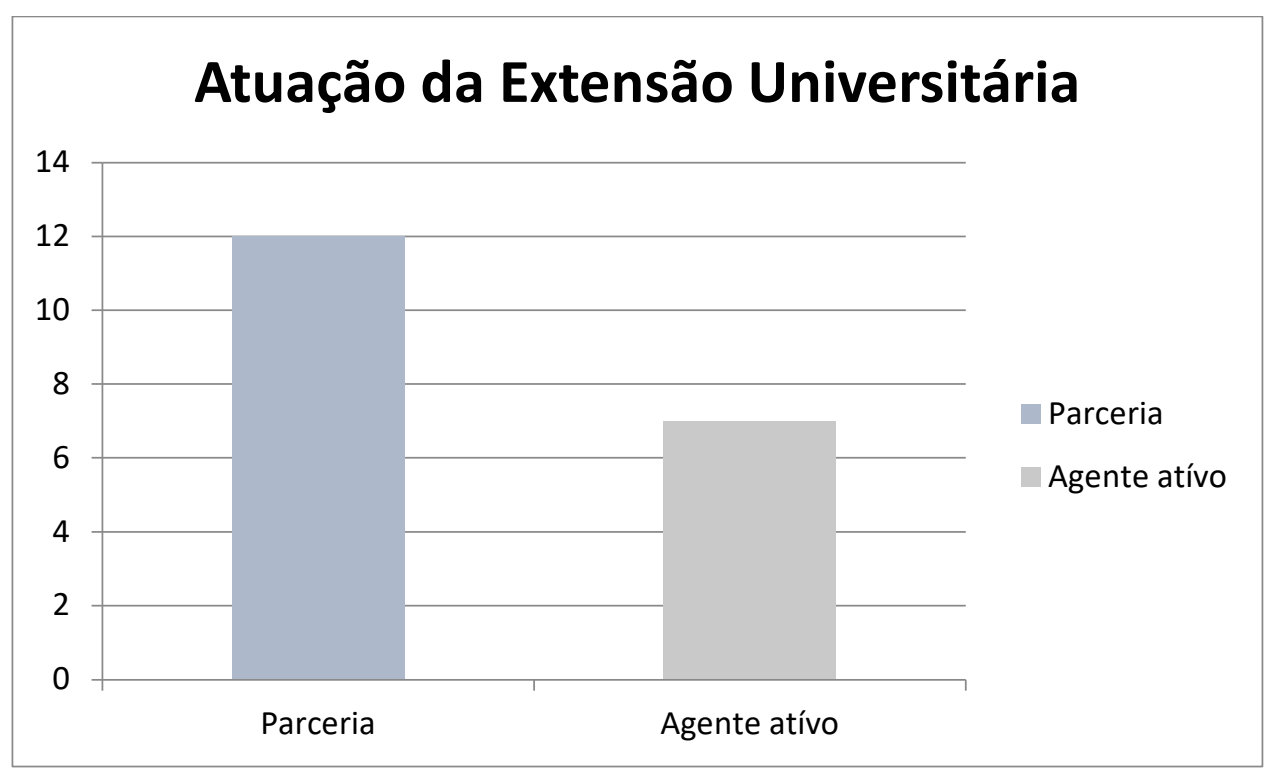

Fonte: Elaborado pelo autor

Ao analisar o envolvimento dos parceiros nos projetos de extensão, fica claro que alguns agentes participam de maneira mais contínua do que outros. Além disso, algumas barreiras externas prejudicam a efetividade de algumas ações. Sobre esses aspectos, é importante observar o que diz o PS4 (2020):

Houve por muito tempo um distanciamento entre o poder público local e o IFPB, por questões diversas. Durante muito tempo desenvolvíamos de maneira isolada ações que poderiam ser trabalhadas em conjunto e trazer benefícios maiores para o município. Várias ações culturais foram desenvolvidas de maneira isolada, mas com essa nova gestão queremos trabalhar cada vez mais em conjunto com o IFPB. A visão da gestão atual é justamente de trabalhar de maneira mais integrada com os diversos parceiros da cidade (PS4, 2020).

Com relação ao trabalho de extensão em conjunto, percebe-se que os dois núcleos em estudo utilizam essa prática, conforme informado por ambas as coordenadoras. Contudo, essa relação integrada ainda ocorre de maneira singela, ou seja, apenas algumas ações são desenvolvidas em conjunto. 
Ao questionar os participantes sobre o apoio da equipe gestora do Campus, foi possível compreender que o CPEX possui uma visão positiva, ou seja, ele acredita que recebeu o apoio adequado para realização de suas atividades, como demonstra o gráfico seguinte.

Gráfico 3 - Apoio da equipe gestora do Campus

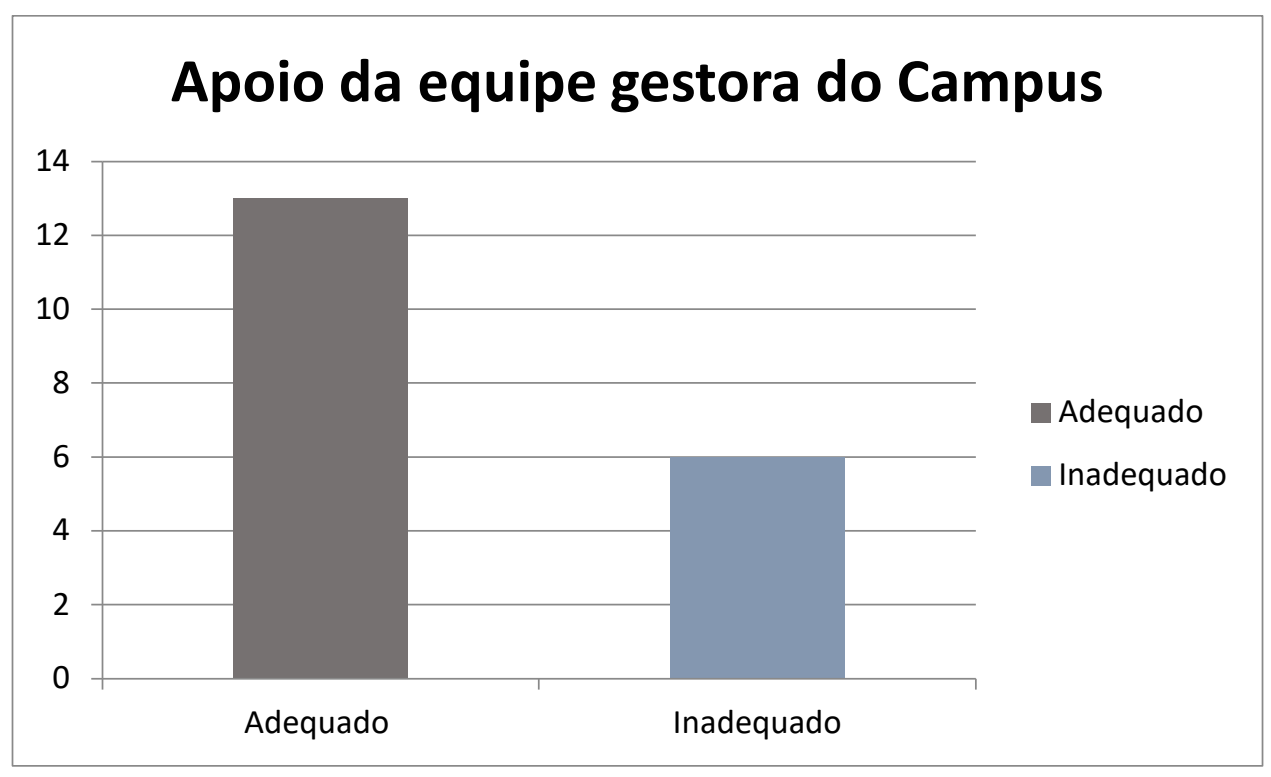

Fonte: Elaborado pelo autor

Por outro lado, a coordenadora do NUPACC relatou que seria mais interessante desmembrar a coordenação em duas, conforme ocorre em outras unidades da instituição. Todavia, o CPEX vê essa unificação de maneira positiva, pois pode trabalhar as ações de maneira integrada e contínua. Portanto, é importante estabelecer uma maior integração entre os atores para minimizar esses aspectos relatados.

Por fim, a coordenadora do DMDC expressa grande satisfação com o apoio que recebe dos diversos âmbitos da gestão do IFPB. Além disso, informou que desde o ano de 2015 todos os projetos do núcleo foram aprovados e receberam taxas de bancada e bolsas para os discentes. Contudo, destacou a necessidade de uma sala específica para desenvolver as atividades relacionadas aos núcleos de extensão do Campus Cabedelo.

Partindo para a análise das dimensões da sustentabilidade, compreende-se que a atuação do IFPB está pautada em valores que englobam a sustentabilidade em suas variadas dimensões. Assim, os núcleos de extensão em análise contribuem diretamente com a dimensão social. Nesse sentido, diversas ações foram desenvolvidas para contribuir com a 
formação do cidadão, geração de renda e uma maior participação da comunidade. Evidenciase, na percepção de um membro da comunidade, os benefícios que os projetos de extensão trouxeram para a sua vida:

Eu fiz vários cursos, aprendi a parte de higienização e aprendi a reaproveitar todas as partes dos alimentos. Também aprendi a fazer artesanatos, porque eu trabalho em uma $\mathrm{ONG}$ e criamos algumas peças para gerar uma renda extra. Eu posso dizer que foram muitos benefícios, desde o aprendizado de coisas que faço na minha casa até a uma renda extra que conseguimos arrecadar para a ONG (MC2, 2020).

Sobre a dimensão Ambiental, identificou-se que é a mais lembrada quando se trata do termo Sustentabilidade, tendo em vista que os estudos iniciais dessa temática englobavam principalmente as questões ambientais. Além disso, é possível concluir que essa dimensão é abordada de maneira abrangente em diversas ações do Campus Cabedelo.

A dimensão Econômica, junto com as duas dimensões anteriores, compõe a tríade primária do termo Sustentabilidade. Percebe-se que essa dimensão está enraizada nos princípios institucionais do IFPB, assim como ocorre com as dimensões anteriores. Portanto, foi possível evidenciar que os membros da comunidade demonstraram que as ações desenvolvidas promoveram melhorias em relação a questões econômicas desses atores. Assim, fica claro que os projetos realizados são efetivos e promovem resultados realistas e de maneira positiva na comunidade de Cabedelo.

Ao dar continuidade à análise das dimensões da Sustentabilidade previamente selecionadas, inicia-se nessa etapa a compreensão da dimensão Cultural e sua aplicação no IFPB. Os discentes entrevistados que participaram de projetos de extensão enfatizaram a grande importância do conhecimento adquirido por meio dessa experiência. Ademais, foi possível perceber que esses alunos possuem uma visão ampliada da sustentabilidade, ou seja, foi possível identificar em suas falas a relação das práticas de extensão com as cinco dimensões da sustentabilidade.

Os membros da comunidade que participaram dos projetos do NUPACC destacaram a relevância do desenvolvimento de práticas culturais no município. Assim, o MC5 destacou o aprendizado de técnicas de artesanato e o MC6 ressaltou a sua participação em diversas atividades que contribuíram para o crescimento pessoal e profissional.

Portanto, infere-se das informações coletadas que, apesar de identificar alguns pontos a melhorar, como o distanciamento do poder público local, o NUPACC desenvolve projetos relacionados à promoção cultural de Cabedelo e possui uma avaliação positiva diante dos agentes entrevistados. Assim, ressalta-se a necessidade de minimizar os obstáculos mencionados para que o IFPB possa beneficiar ainda mais a comunidade local.

Por fim, pode-se afirmar que todas as ações da instituição se relacionam de alguma forma com a dimensão Política. Assim, a extensão universitária do Campus atua em questões 
que envolvem o poder público local, estadual e federal. Tal atuação ocorre na tentativa de minimizar problemas socioambientais, ampliar a participação da comunidade local nas decisões políticas e promover uma maior igualdade social.

Com isso, baseando-se nos dois núcleos aqui analisados, afirma-se que ambos desempenham um papel transformador no município. Assim, tanto o DMDC como o NUPACC foram avaliados de maneira positiva por todos os entrevistados. Além disso, foram salientados pontos relevantes que merecem destaque e são de fundamental importância para análise desse estudo.

Ao longo da história é possível identificar que a educação se mostra como a melhor forma de transformar a sociedade, gerando um pensamento crítico e propondo soluções para uma sociedade mais sustentável, como explicita Martens (2006). Os universitários precisam estar preparados para tomar decisões em prol de um futuro sustentável, fator que depende da consciência, conhecimento e valores adquiridos na universidade. Na Agenda 21, o capítulo 36 trata sobre a Promoção do Ensino, da Conscientização e do Treinamento, visando a contribuir com o desenvolvimento sustentável nas diversas dimensões que ele abarca. A Educação, para o Desenvolvimento Sustentável, abrange a transmissão de conhecimento e valores, inclusive na Extensão Universitária (NEPP-DH, 2020).

Razak et al. (2013) esclarece que o impacto das universidades para a sustentabilidade é considerável no que tange à promoção da prosperidade das comunidades onde estão inseridas. Tais instituições influenciam no comportamento e no desenvolvimento ambiental social e econômico, pontos destacados pelos participantes, dentro e fora das comunidades às quais pertencem (LOZANO et al., 2013). Verifica-se que essas instituições são elementos essenciais na educação da sociedade para a sustentabilidade, não só como disseminadores dos princípios, mas também com a integração sistemática da sustentabilidade em suas operações (HANSEN; LEHMANN, 2006).

O conceito de sustentabilidade aponta a indissociabilidade das múltiplas dimensões e ações de Pesquisa, Ensino e Extensão, que atuam para a construção de sociedades responsáveis, solidárias e sustentáveis. Por intermédio das entrevistas elaboradas, pode-se identificar que a extensão universitária atua em prol da sustentabilidade em suas diversas dimensões, buscando reduzir os impactos ambientais; promover um acesso às classes mais necessitadas a bens e serviços; estimular uma distribuição equitativa das riquezas; respeitar a identidade local e viabilizar uma organização coletiva de autogestão.

De certo que as ações descritas neste estudo e os resultados aferidos apontam que a Universidade com o seu caráter extensionista motivou os participantes, promovendo a valorização e a identificação, buscando métodos mais assertivos de realizar suas atividades de Extensão. Contudo, muito ainda se pode fazer para implementar o conceito de sustentabilidade no contexto de Cabedelo/PB. 
As instituições de ensino superior devem alinhar a sustentabilidade ao tripé: ensino, pesquisa e extensão, planejando ações e políticas que promovam o bem-estar e a melhoria na qualidade de vida de todos os envolvidos no processo educativo, proporcionando a construção de uma sociedade mais justa e sustentável em todas as esferas (WALCHOZ; CARVALHO, 2015).

\section{Considerações Finais}

O presente estudo teve como objetivo principal analisar as ações de extensão universitária do Instituto Federal da Paraíba (IFPB), em Cabedelo/PB, e sua relação com o desenvolvimento da compreensão da comunidade acadêmica e municipal sobre a sustentabilidade. Para fomentar a análise foi realizada uma pesquisa de campo com 19 participantes associados a diversos núcleos da Instituição em questão.

Pode-se depreender que o conhecimento da comunidade sobre a sustentabilidade está atrelado às três dimensões básicas (Ambiental, Econômica e Social). Já em relação à extensão universitária, a maioria dos participantes acredita que consiste em uma relação de trabalho em conjunto, enquanto que apenas sete entrevistados perceberam a extensão como responsabilidade exclusiva do instituto. Nesse prisma, cabe esclarecer que a sustentabilidade apresenta cinco dimensões interligadas: ambiental, social, econômica, cultural e política.

Identificou-se que alguns parceiros sociais participam de maneira mais contínua do que outros. Além disso, os núcleos de extensão mais atuantes dentro da instituição procuram realizar ações em conjunto, porém, esse esforço isolado não é suficiente para integrar os outros núcleos existentes no Campus Cabedelo ou nas demais unidades do IFPB.

Ao analisar a relação entre a equipe gestora do instituto e a extensão universitária, foi possível perceber que tanto o coordenador de Pesquisa e Extensão quanto as coordenadoras dos núcleos possuem uma avaliação positiva a respeito da atuação da equipe gestora em ações de extensão.

Verifica-se que o tema sustentabilidade encontra poucos subsídios na literatura considerando suas outras dimensões, além da esfera ambiental. A universidade mostra-se como um instrumento de grande importância social, dada sua atuação em projetos de pesquisa, ensino e extensão. A extensão universitária permite que o aluno tenha consciência de como o conhecimento produzido pode servir à sociedade. Ademais, as instituições de ensino superior possuem um papel de relevância para as transformações sociais em prol de um futuro sustentável, incutindo valores, comportamentos e estilos de vida para que a sociedade identifique a importância da abordagem de questões que afetam seu porvir.

Por fim, o estudo visou à identificação da relação que a extensão universitária do Campus Cabedelo mantinha com as cinco dimensões da sustentabilidade selecionadas 
(Social, Ambiental, Econômica, Cultural e Política). As respostas analisadas permitiram o reconhecimento do impacto das ações implementadas pela instituição, considerando todas as dimensões da sustentabilidade, visto que estimulam a distribuição equitativa das riquezas (aspecto econômico); acesso a bens e serviços para as classes menos abastadas (aspecto social); reduz os impactos ambientais; promove o reconhecimento da identidade local (aspecto cultural) e figura como cerne da dimensão política.

Nesse sentido, as ações do instituto geram impacto positivo na comunidade e os projetos desenvolvidos estão em conformidade com o que dizem os autores a respeito das dimensões da sustentabilidade. Com isso, ficou claro que os projetos realizados foram efetivos, promoveram resultados realistas e de aplicação prática na comunidade de Cabedelo.

\section{Referências}

BARDIN, Laurence. Análise de conteúdo. São Paulo: Edições 70, 2011.

BOTTONI, A., Sardano, E. J., \& Costa Filho, G. B. Uma breve história da Universidade no Brasil: de Dom João a Lula e os desafios atuais. In: COLOMBO; Sonia Simões (Org.). Gestão universitária: os caminhos para a excelência. Porto Alegre: Penso, 2013.

BUFFA, E., \& PEREIRA, R. C. Extensão: meio de comunicação entre universidade e comunidade. EccoS Revista Científica, São Paulo, SP, v. 9, n. 1, 2007.

CASTRO, M. C. Desenvolvimento sustentável: a genealogia de um novo paradigma. Economia e Empresa, São Paulo, SP, v. 3, n. 3, 1996.

I FORPROEX - Encontro de Pró-Reitores de Extensão das Universidades Públicas Brasileiras. Conceito de extensão, institucionalização e financiamento. Brasília, 1987.

FORPROEX - Fórum de Pró-Reitores de Extensão das Instituições Públicas de Educação Superior Brasileiras. Política nacional de extensão universitária. Manaus, 2012.

FRIZZO, G. F. E., MARIN, E. C., \& SCHELLIN, F. O. A extensão universitária como elemento estruturante da universidade pública no Brasil. Currículo sem Fronteiras, v. 16, n. 3, 2016.

GIL, A. C. Como elaborar projetos de pesquisa. 4. São Paulo: Ed. Atlas, 2002.

HANSEN, Jens Aage; LEHMANN, Martin. Agents of change: universities as

development hubs. Journal of Cleaner Production, v. 14, n. 9-11, p. 820-829, 2006. 
HUNGER, D., ROSSI, F., PEREIRA, J. M., \& NOZAKI, J. M. O Dilema Extensão

Universitária. Educação em Revista. Belo Horizonte, MG, v.30. n.03, 2014.

IAQUINTO, B. O. A sustentabilidade e suas dimensões. Revista da ESMESC.

Florianópolis, SC, v. 25, n. 31, 2018.

IFPB. Instituto Federal Da Paraíba. Plano de Desenvolvimento Institucional 2015-

2019.Disponível em:http:/editor.ifpb.edu.br/institucional/pdi/PDI_2015_2019.pdf/view.

JEZINE, E. A Crise da Universidade e o Compromisso Social da Extensão

Universitária. João Pessoa: UFPB / Editora Universitária, 2006.

LOZANO, Rodrigo et al. Declarations for sustainability in higher education: becoming better leaders, through addressing the university system. Journal of Cleaner Production, v. 48, p. 10-19, 2013.

MARTENS, Pim. Sustainability: science or fiction?. Sustainability: Science, Practice and Policy, v. 2, n. 1, p. 36-41, 2006.

MOIMAZ, S. A. S., BORDIN, D., GOMES, A. M. P., FADEL, C. B., GARBIN, C. A S., \& SALIBA, N. A. Extensão universitária na ótica de acadêmicos: o agente fomentador das Diretrizes Curriculares Nacionais. Revista da ABENO, v.15, n.4, 2015.

NEPP - DH. Agenda 21 - Promoção do ensino, da conscientização e do Treinamento. Núcleo de Estudos e Políticas Públicas em Direitos Humanos Suely Souza de Almeida. Disponível em: http://www.nepp-dh.ufrj.br/onu13-3-36.html

NEUENDORF, Kimberly A. Beyond description: an integrative Model of Content Analysis. The Content Analysis Guidebook. Thousand Oaks, CA: Sage Publications, Inc, p. 47-70, 2002.

OLABUENAGA, J.I. R.; ISPIZUA, M.A. La descodificacion de la vida cotidiana: metodos de investigacion cualitativa. Bilbao, Universidad de deusto, 1989.

PÓVOAS, M. S. O Amor na Sociedade de Risco: A Sustentabilidade e as Relações de Afeto. In: ARMADA, C. A., SOUZA, M. C. S. A. (Org.). Sustentabilidade Meio Ambiente e Sociedade: reflexões e perspectiva. - Umuarama: Universidade Paranaense - UNIPAR, 2015. 
PRODANOV, C. C., \& FREITAS, E. C. Metodologia do trabalho científico: métodos e técnicas da pesquisa e do trabalho acadêmico. 2. ed, Novo Hamburgo: Feevale, 2013.

RAZAK, Dzulkifli Abdul et al. Alternative University Appraisal (AUA): reconstructing universities' ranking and rating toward a sustainable future. In: Sustainability Assessment Tools in Higher Education Institutions. Springer, Cham, 2013. p. 139-154.

ROVATI, J., \& D’OTTAVIANO, C. Os territórios da extensão universitária. In: Para além da sala de aula: extensão universitária e planejamento urbano e regional. São Paulo: FAUUSP, 2017.

SACHS, I. Caminhos para o desenvolvimento sustentável. 4. ed. Rio de Janeiro: Garamond, 2002.

WACHHOLZ, Chalissa; CARVALHO, Isabel Cristina de Moura. Indicadores de sustentabilidade na PUCRS: uma análise a partir do Projeto Rede de Indicadores de Avaliação da Sustentabilidade em Universidades Latino-Americanas. Revista Contrapontos, Itajaí, 2015. 